\title{
Demonstration of persistent tumor cells 4 weeks after radiofrequency ablation of a pulmonary adenocarcinoma
}

\author{
Stéphane Renaud, Marco Schiavon, MD, Nicola Santelmo, MD, and Gilbert Massard, MD, PhD, \\ Strasbourg, France
}

Radiofrequency ablation (RFA) has gained steadily increasing interest as an alternative to surgery. Previous reports on primary nonsmall-cell lung cancer (NSCLC) have shown a local control rate after RFA varying between $58 \%$ and $68 \%$ (median follow-up between 17 and 28 months), with an overall 3-year survival rate of $47 \%$. $^{1,2}$ Pneumothorax represents the main complication of RFA, occurring in $17 \%$ to $68 \%$ of procedures. ${ }^{1,2}$ We report a case of a wedge resection performed 4 weeks after RFA containing $40 \%$ viable adenocarcinoma cells.

\section{CLINICAL SUMMARY}

A 58-year-old patient with stage 3 smoking-induced chronic obstructive pulmonary disease (forced expiratory volume at 1 second at $43 \%$ of predicted), presented with a nodular adenocarcinoma of the left upper lobe measuring $15 \mathrm{~mm}$ (Figure 1, A). Staging, including brain and abdominal computed tomography (CT) scan failed to identify metastases. Because of ischemic heart disease with left ventricular ejection fraction at $50 \%$, the patient was deemed unfit for surgery without discussion at the multidisciplinary board, and was offered percutaneous RFA.

An expandable monopolar needle $4 \mathrm{~cm}$ in diameter was inserted using CT guidance (Figure 1,B). The session lasted 7 minutes with a wattage-current setting of $40 \mathrm{~W}$. CT scan after the procedure showed a successful ablation, characterized by a peritumoral ground glass opacity, and obviated a pneumothorax requiring drainage (Figure 1, $C$ ). The patient was referred to us for surgical revision 4 weeks later because of a major persisting air leak. Exploration of the pleural cavity disclosed a necrotic lesion in the left upper lobe measuring $5 \mathrm{~cm}$, centered by a $3-\mathrm{mm}$ pin-shaped hole with escaping air (Figure 2, A). Lobectomy was considered to present a high risk for vascular injury because of the fragility of the tissues, hilar inflammation, and enlarged nodes. Hence, we decided to

\footnotetext{
From the Department of Thoracic Surgery, New Civil Hospital, Strasbourg, France. Disclosures: Authors have nothing to disclose with regard to commercial support. Received for publication May 15, 2012; revisions received June 22, 2012; accepted for publication July 25, 2012; available ahead of print Sept 10, 2012.

Address for reprints: Nicola Santelmo, MD, Service de Chirurgie Thoracique, Nouvel Hôpital Civil, 1 Place de l'Hôpital, 67000 Strasbourg, France (E-mail: nicola. santelmo@chru-strasbourg.fr).

J Thorac Cardiovasc Surg 2012;144:e111-3

$0022-5223 / \$ 36.00$

Copyright (c) 2012 by The American Association for Thoracic Surgery

http://dx.doi.org/10.1016/j.jtcvs.2012.07.028
}

perform a wedge resection. Postoperative course was uneventful; chest tubes were withdrawn on Postoperative Day 4, and the patient was discharged on Postoperative Day 6.

Pathologic examination after tissue fixation and staining of slides with hematoxylin-eosin showed evidence of persistence of $40 \%$ viable adenocarcinoma cells with preserved cytoplasm, nuclei, and mitotic figures, located both close and at distance of vessels (Figure 2, $B$ and $C$ ). To assess the proliferative potential, an immunohistochemical analysis was performed with anti-Ki67 antibodies (clone SP6, Neomarkers; Thermo Scientific Pierce Products, Rockford, Ill), which revealed nuclear marking of a vast majority of these cells (Figure 2, D).

\section{DISCUSSION}

RFA is a procedure in which high-frequency electrical currents are delivered through an electrode, creating heat that coagulates surrounding tissues. Close vicinity of the tumor to blood vessels is an important limitation factor, because heat may be dissipated by blood flow. ${ }^{3}$ This "heat sink effect" might explain inefficiency in our case.

Data regarding efficacy of RFA are limited. Most available reports pool primary and metastatic tumors with a short-term follow-up. In our case, histologic analysis was achieved 4 weeks after RFA, revealing persistence of $40 \%$ of viable cells, of which a vast majority still showed proliferative potential, signed by Ki67 immunostaining. Unfortunately, we have no histologic documentation of the immediate postintervention status. We only can hypothesize that either the initial destruction concerned only $60 \%$, or that there was a proliferation from a smaller population of persistent viable cells. Our case suggests that persistence of viable cells may evolve to proliferation with tumor growth and metastatic spread. Furthermore, Schneider and colleagues ${ }^{3}$ reported that effectiveness of RFA may be modulated by the histologic subtype. He noted that all incomplete ablations concerned adenocarcinoma. Our case adds to this observation.

The main nonsurgical alternative to RFA is stereotactic radiotherapy (SR). Published data concerning primary NSCLC involve larger populations than published data concerning RFA, and obviate a more satisfactory local control rate exceeding $90 \%$ at 3 years; 5-year overall survival rates range up to $78 \%{ }^{4,5}$ Further, RFA is flawed by a high incidence of procedure-related pneumothorax, 


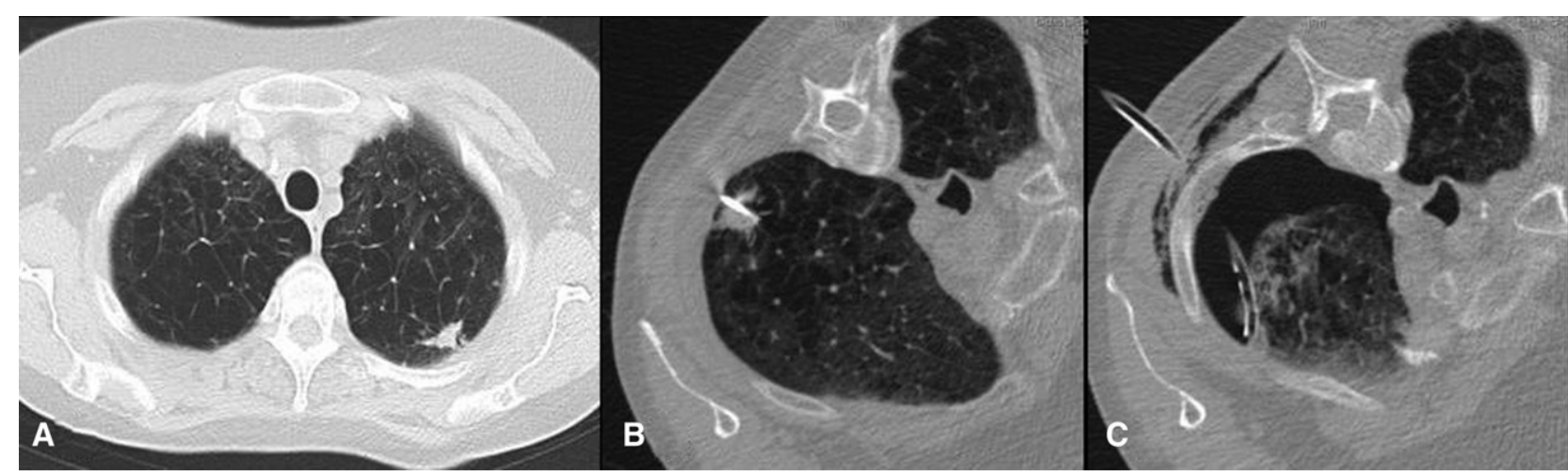

FIGURE 1. Computed tomography scans taken before, during, and after the treatment. A, Supine chest computed tomography scan performed before radiofrequency treatment showing lesion located in left upper lobe. B, Prone computed tomography scan during radiofrequency treatment with correct insertion of the probe in the lesion. C, Prone computed tomography scan after procedure showing a successful radiological procedure and a pneumothorax.

which occurs in $16 \%$ to $68 \%$ of procedures. ${ }^{1,2}$ Although air leaks usually spontaneously seal, some patients will require prolonged drainage or paradoxical surgical management despite initial contraindication. Therefore, referring to available evidence, SR is preferable to RFA as local treatment when surgery is deemed unsuitable.

Mediastinal lymphadenectomy is one of the fundamentals of oncologic resection, both to ascertain completeness of resection and accuracy of nodal staging. This requirement is not met with purely local treatments such as RFA or SR. We decided against node dissection in this case because of major inflammatory changes in the surrounding mediastinal area.

\section{CONCLUSIONS}

The first treatment option to consider for patients with marginal functionality with limited disease is a sublobar resection combined with lymph node dissection. The second option is SR, because its medium-term results approach those obtained with surgery. Finally, disease management options for any patient with NSCLC should be discussed by a multidisciplinary board that includes a certified thoracic surgeon.

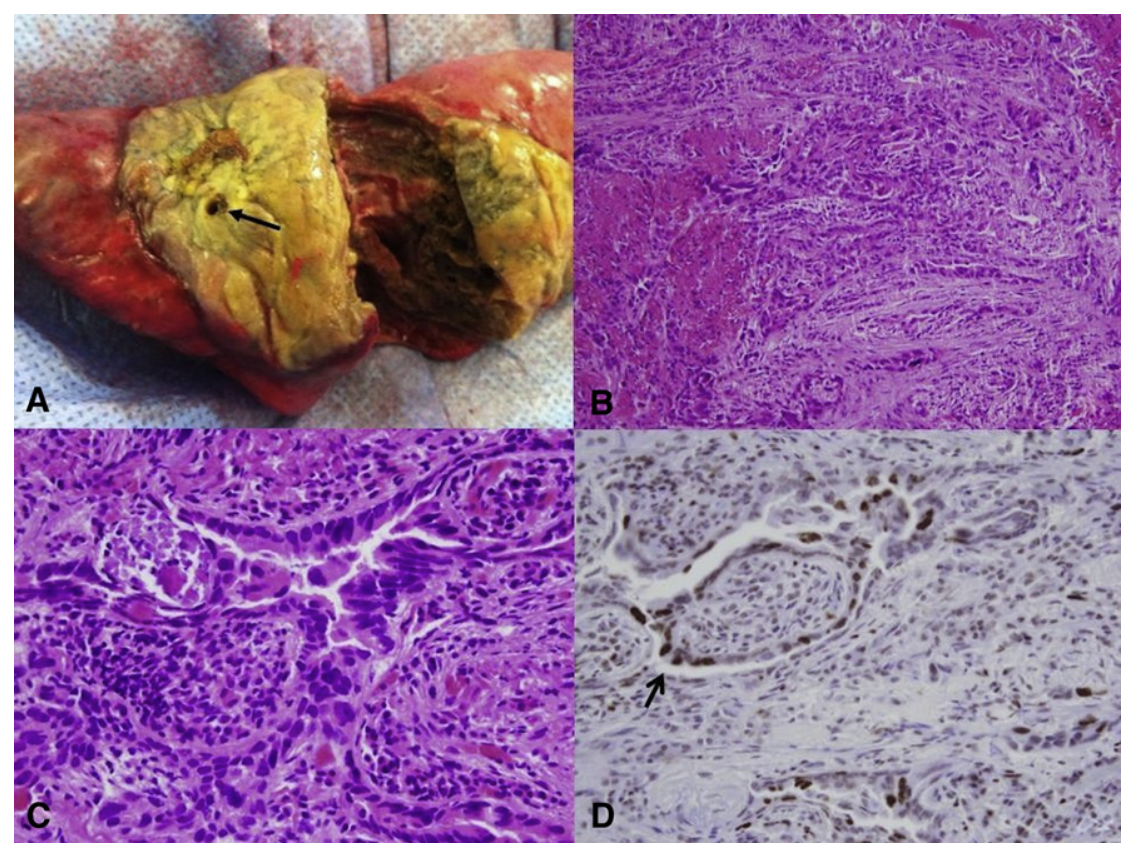

FIGURE 2. A, Intraoperative view of the lesion after wedge resection. B and C, Pathologic examination of the specimen marked with hematoxylin \& eosin stain confirming the presence of adenocarcinoma with suspected multiple proliferating cells. D, Immunohistochemical analysis using anti-Ki67 antibody confirming the presence of major foci of viable neoplastic cells (black arrow) representing $>40 \%$ of the tumor. 


\section{References}

1. Pennathur A, Luketich JD, Abbas G, Chen M, Fernando HC, Gooding WE, et al. Radiofrequency ablation for the treatment of stage I non-small cell lung cancer in high-risk patients. J Thorac Cardiovasc Surg. 2007;134:857-64.

2. Lanuti M, Sharma A, Digurmarthy SR, Wright CD, Donahue DM, Wain JC, et al. Radiofrequency ablation for treatment of medically inoperable stage I non-small cell lung cancer. J Thorac Cardiovasc Surg. 2009;137:160-6.

3. Schneider T, Reuss D, Warth A, Schnabel PA, Von Deimling A, Herth FJF, et al. The efficacy of bipolar and multipolar radiofrequency ablation of lung neo- plasms: results of an ablate and resect study. Eur J Thorac Surg. 2011;39: 968-73.

4. Baumann P, Nyman J, Hoyer M, Wennberg B, Gagliardi G, Lax I, et al. Outcome in a prospective phase II trial of medically inoperable stage I non-small-cell lung cancer patients treated with stereotactic body radiotherapy. J Clin Oncol. 2009;27:3290-6.

5. Nagata Y, Takayama K, Matsuo Y, Norihisa Y, Mizowaki T, Sakamoto T, et al. Clinical outcomes of a phase I/II study of $48 \mathrm{~Gy}$ of stereotactic body radiation therapy in 4 fractions for primary lung cancer using a stereotactic body frame. Int $J$ Radiation Oncology Biol Phys. 2005;5:1427-31.

\title{
The role of methylene blue in serotonin syndrome following cardiac transplantation: A case report and review of the literature
}

\author{
Kendra J. Grubb, MD, ${ }^{a}$ Jamie L. W. Kennedy, MD, ${ }^{b}$ James D. Bergin, MD, ${ }^{b}$ Danja S. Groves, MD, PhD, ${ }^{c}$ and \\ John A. Kern, MD, ${ }^{a}$ Charlottesville, Va
}

Vasoplegic syndrome (VS) is a common complication of cardiopulmonary bypass, with an incidence reported between $5 \%$ and $25 \%$ for all cardiac operations. ${ }^{1,2}$ Associated with increased morbidity and mortality, ${ }^{2,3}$ VS is characterized by severe systemic arterial hypotension (mean arterial pressure, $<50 \mathrm{~mm} \mathrm{Hg}$ ) and low systemic vascular resistance $\left(<800\right.$ dyne $\left./ \mathrm{s} / \mathrm{cm}^{5}\right) .{ }^{1,3}$ The syndrome is particularly troubling in orthotopic heart transplant recipients as a result of the untoward effects of increased fluid and vasopressor requirements for resuscitation. Furthermore, VS is reported to occur in as many as $45 \%$ of patients with a ventricular assist device at the time of transplantation, making this a particularly high-risk surgical population. ${ }^{4}$

The blunting of nitric oxide release has been hypothesized to counter the endothelial dysfunction thought to cause vasoplegia. Methylene blue interacts with nitric oxide-mediated pathways via a number of mechanisms, including direct nitric oxide binding, inhibition of soluble guanylate cyclase, and inhibition of nitric oxide synthase..$^{5-7}$ Methylene blue has been shown to reverse refractory hypotension associated with vasoplegia. ${ }^{8-10}$ Furthermore, the benefits of methylene blue for the

\footnotetext{
From the Division of Thoracic, Cardiac, and Vascular Surgery, ${ }^{\mathrm{a}}$ the Division of Cardiovascular Medicine, ${ }^{\mathrm{b}}$ and the Department of Anesthesiology, ${ }^{\mathrm{c}}$ University of Virginia Health Systems, Charlottesville, Va.

Disclosures: Authors have nothing to disclose with regard to commercial support.

Received for publication April 23, 2012; revisions received June 22, 2012; accepted for publication July 25, 2012; available ahead of print Sept 17, 2012.

Address for reprints: Kendra J. Grubb, MD, University of Virginia Health System, Division of Thoracic, Cardiac, and Vascular Surgery, PO Box 800679, Charlottesville, VA 22908 (E-mail: kg8fg@virginia.edu).

J Thorac Cardiovasc Surg 2012;144:e113-6

$0022-5223 / \$ 36.00$

Copyright (C) 2012 by The American Association for Thoracic Surgery

http://dx.doi.org/10.1016/j.jtcvs.2012.07.030
}

treatment of VS have been well documented in cardiac surgery, and its usage associated with reduced mortality and morbidity. ${ }^{11,12}$

In an effort to circumvent the morbidity and mortality associated with VS, we have implemented successfully an intraoperative protocol that includes administration of methylene blue for VS resistant to vasopressor treatment. Until now, scant information has been reported about the untoward effects of methylene blue in the cardiac transplant patient population. Herein, we describe the first case of methylene blue-induced serotonin toxicity in a patient after cardiac transplant. A review of the current literature and U.S. Federal Drug Administration (FDA) warnings are included.

\section{CASE REPORT}

A 60-year-old male with history of nonischemic cardiomyopathy and end-stage heart failure underwent placement of a left ventricular assist device (LVAD) along with replacement of a mechanical aortic valve with a porcine prosthesis in March 2011. His LVAD course was complicated by multiple driveline infections with Pseudomonas, Serratia, and, most recently, Achromobacter. He was therefore listed for heart transplantation as a United Network for Organ Sharing status 1A. A donor organ became available and he was brought to the hospital for preoperative management of anticoagulation and preparation for transplant. Comorbidities included insulin-dependent diabetes mellitus, hypertension, obesity status-post gastric bypass surgery, peptic ulcer disease, chronic kidney disease, gout, and depression, for which he was taking escitalopram $20 \mathrm{mg}$ per ora daily as well as trazodone $100 \mathrm{mg}$ daily at bedtime.

He underwent a third-time redo sternotomy with femoral cannulation and initiation of cardiopulmonary bypass. After the aortic crossclamp was placed, he was noted to have 